\title{
HENRY SCHULTZ' LEVENSWERK: STATISTISCHE BEPALING VAN VRAAGCURVEN.
}

Door Prof. J. Tinbergen.

De nog jonge hoogleraar aan de universiteit van Chicago Henry Schultz is onlangs met zijn vrouw en twee dochters bij een autoongeluk om het leven gekomen. Dit treurige bericht voor hen die de bekwame, bescheiden, innemende onderzoeker hebben gekend is voor mij aanleiding om zijn kort tevoren verschenen boek wat uitvoeriger te bespreken. Dit werk ${ }^{1}$ ) toch is een samenvatting van al het onderzoekingswerk door Schultz verricht op het gebied van de theorie en vooral de statistische bepaling van vraagcurven en -functies; en de wetenschap mag dankbaar zijn dat dit werk is kunnen voltooid worden. Het zal ongetwijfeld een boek zijn dat zeer vele van zijn tijdgenoten overleeft. Opgedragen aan Henry Ludwell Moore, die op het gebied van de statistische bepaling van vraagcurven de pionier is, bouwt het op diens werk voort en geeft vooral op het gebied van de vraag naar verwante goederen (rund-, varkens- en schapenvlees; thee, koffie en suiker) zeer waardevolle originele bijdragen. Het is tevens geworden tot een compendium van alle literatuur over de theorie der vraagfuncties bij vrije concurrentie, welke literatuur door Schultz met de hem eigen nauwgezetheid systematisch wordt weergegeven en van commentaar voorzien. Daar de auteur jarenlang aan het boek gewerkt heeft ten dele als gevolg van tegenslagen bij het werk - is echter de allernieuwste literatuur in enige slothoofdstukken toegevoegd. In de bijlagen treffen we een zeer uitvoerige uiteenzetting aan over de mathematisch-statistische methoden die hij heeft aangewend, welk overzicht alleen reeds een bruikbaar leerboekje zou vormen.

De indeling van het boek is aldus: in een eerste gedeelte worden. de theoretische fundamenten van het werk besproken; in het

1) The Theory and Measurement of Demand. University of Chicago Press, 1938; XXXII + 817 blz., $66+$ XIII tabellen en 106 figuren. (Social. Science Studies, No. XXXVI). 
tweede de resultaten van statistische bepalingen van enkelvoudige vraagcurven en in het derde de vraag naar verwante goederen.

Het eerste gedeelte bespreekt de ontwikkeling van het begrip „vraag naar een bepaald goed" vanaf Say en vooral Cournot via Walras, Pareto, Marshall, tot de moderne schrijvers als Allen en Hicks. In verband met de mogelijkheid dat "de nuttigheid" van een gegeven hoeveelheid van zeker goed voor een gegeven persoon onmeetbaar is, heeft Pareto, zoals men weet, de zgn. indifferentiecurven of -vlakken, -ruimten, enz. ingevoerd, welke in principe in elk geval meetbaar zijn. Dit zijn curven of vlakken, enz. waarvan elk punt representeert een bepaalde goederencombinatie ( $x$ eenheden van goed $1, y$ van goed 2 , enz.) in het bezit van een bepaald persoon en waarvan bovendien geldt dat elk dezer combinaties een even grote bevrediging schenkt aan die persoon. Men kan wèl door ondervraging of uit de gedragingen der mensen te weten komen of twee combinaties gelijk nut hebben dan wel of een van beide een hoger nut heeft. Maar het is zeer twijfelachtig of men kan uitmaken of een combinatie $C$ evenwel veel meer nut dan $B$ geeft als $B$ t.o.v. A. Toch zou dat nodig zijn wilde men de nuttigheid kunnen meten. Pareto ontkent de mogelijkheid daartoe en slaagt er bovendien in om alle wetten van het economisch handelen af te leiden zonder dat men het nut kan meten. Schultz volgt hem daarbij in 't algemeen; een enkele maal echter wijkt hij van deze gedragslijn af en de desbetreffende stellingen moeten m.i. dan ook als minder algemeen beschouwd worden dan die van Pareto. Zo b.v. in zijn eerste behandeling van het vraagstuk van de complementaire en vervangbare goederen.

De stellingen die Pareto en zijn volgelingen hebben bewezen hebben vooral betrekking op de kwestie: hoeveel zal een economisch subject met een gegeven inkomen en op een markt met gegeven prijs kopen van een bepaald goed? In andere woorden: hoe hangt de gekochte hoeveelheid af van de prijs van het goed en van het inkomen? Deze afhankelijkheid heet zoals men weet vraagfunctie; bestudeert men alleen de afhankelijkheid tussen gegeven prijs en (daaruit volgende) hoeveelheid, dan laat zich dat verband grafisch voorstellen door een curve $^{2}$ ). Eén dergelijke

2) $\mathrm{Bij}$ het tekenen van de curve wordt door economen de prijs gewoonlijk verticaal, door wiskundigen horizontaal afgezet, dit laatste omdat het in de wiskunde algemeen gebruikelijk is om de $z \mathrm{gn}$. onafhankelijk veranderlijke horizontaal af te zetten. Natuurlijk gaat het hier slechts om conventies. 
curve kan slechts gelden voor een vaste waarde van het inkomen en van alle andere factoren die de gevraagde hoeveelheid verder bepalen. Zou men aan b.v. het inkomen een andere waarde toekennen, dan zal de vraagcurve zich ook wijzigen; in het algemeen zal daarbij de richting niet veel veranderen. Vaak wordt aangenomen dat de richting zich in 't geheel niet verandert en wordt daarom gesproken van een verschuiving (shifting) van de vraagcurve.

Behalve het inkomen van de vragende marktpartij kunnen nog andere factoren de gevraagde hoeveelheid beïnvloeden. In het geval van de vraag naar consumptiegoederen met korte levensduur zijn de belangrijkste dezer factoren die voor systematische studie in aanmerking komen de prijzen van andere goederen. Aan dit onderwerp wijdt Schultz zeer veel aandacht. Daarbij komt dan onmiddellijk de bekende kwestie naar voren van de complementaire, onafhankelijke en vervangbare goederen.

Dit onderwerp is nog geenszins afgesloten. Nog onlangs zijn belangrijke nieuwe publicaties er over verschenen, nI. die van Allen en Hicks $^{3}$ ). Het blijkt bij nader inzien niet zo eenvoudig te zijn om te definiëren wat men verstaat onder complementaire goederen, of een der beide andere categorieën.

Het is gemakkelijk genoeg om aan te geven wat men onder volmaakte vervangbaarheid en volmaakte complementariteit heeft te verstaan. Naar mijn smaak is hierin Irving Fisher het beste geslaagd, in zooverre als hij zijn voorbeelden ook geadstrueerd heeft door de vorm van de indifferentiecurven aan te geven die met deze twee uitersten overeenkomen. Het goede voorbeeld van volkomen complementaire goederen is dat van een linker en een rechter schoen. Met grote benadering kan men zeggen dat een afzonderlijke linkerschoen geen waarde heeft, evenmin een afzonderlijke rechterschoen. Tezamen hebben ze wel waarde. De waarde van 6 linkerschoenen en 10 rechterschoenen is practisch gesproken dezelfde als de waarde van 6 linker- en 6 rechterschoenen. Houdt men dit in het oog, dan is gemakkelijk in te zien dat de indifferentiecurven verlopen als in fig. 1 is aangegeven.

Ook is gemakkelijk een voorbeeld van volslagen vervangbare goederen te nemen, nl. twee identieke goederen, b.v. boter uit twee vaten die verder in geen enkel opzicht verschillen. Noemen we ze

3) A Reconsideration of the Theory of Value, Economica 1934, blz. 52 en 196.

Econ. 1939. 


\section{RECHTER}

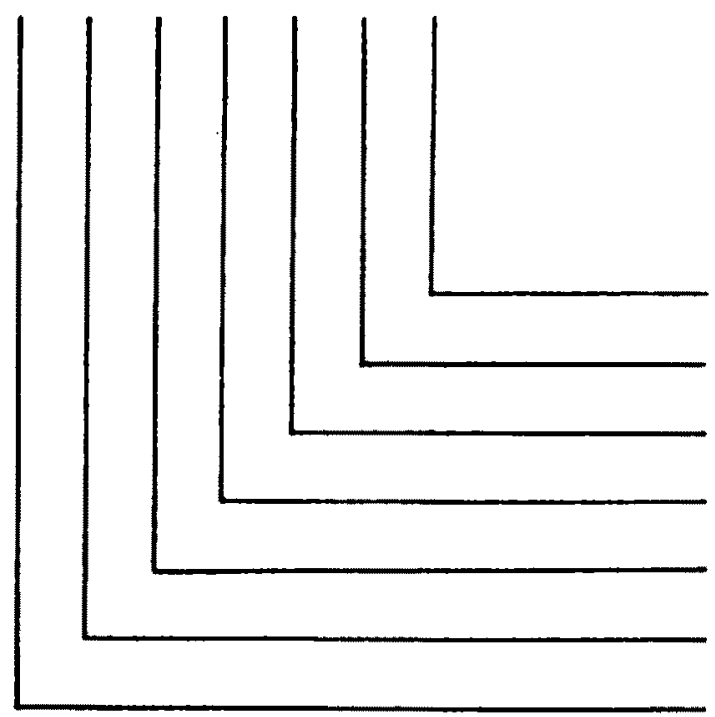

\section{LINKER}

Fig. 1. Indifferentiecurven voor twee volkomen complementaire goederen: rechter en linker schoenen.

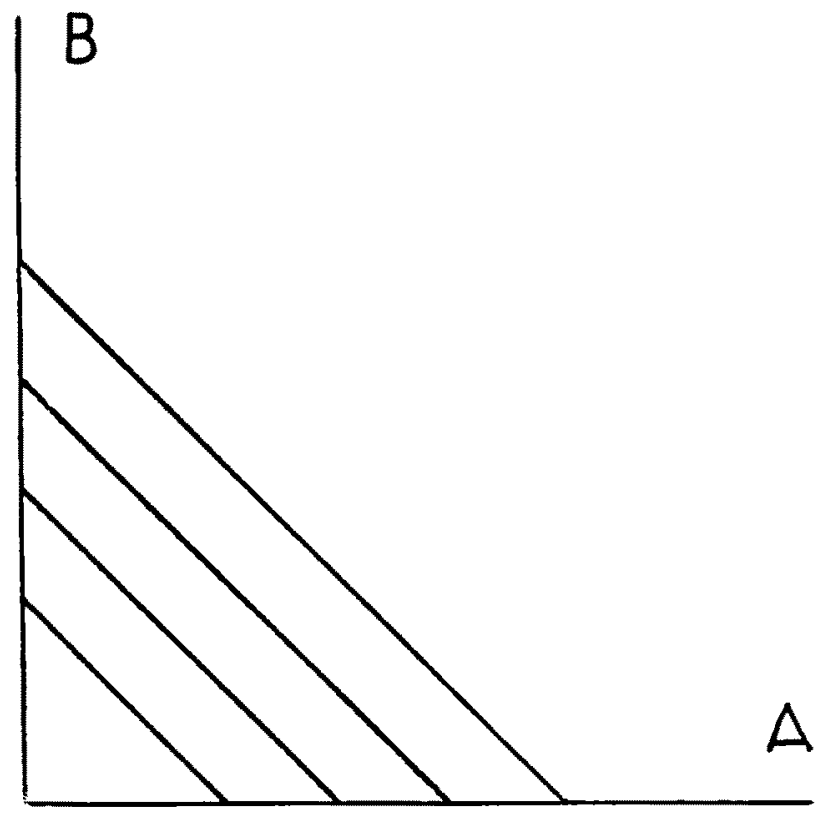

Fig. 2. Indifferentiecurven voor twee volkomen vervangbare goederen. 
gemakshalve boter $\mathrm{A}$ en boter $\mathrm{B}$, dan is het blijkbaar volkomen onverschillig of men $2 \mathrm{~kg}$. boter $A$ en $5 \mathrm{~kg}$. boter $B$ heeft dan wel $3 \mathrm{~kg}$. A en $4 \mathrm{~kg}$. B of $4 \mathrm{~kg}$. A en $3 \mathrm{~kg}$. B, enz. Daarom verlopen hier de indifferentiecurven als in fig. 2 is aangegeven.

Kenmerkend voor volmaakt complementaire goederen is dat men steeds gelijke hoeveelheden van beide zal vragen. Als dus de prijs van het ene goed verlaagd wordt zal de vraag naar beide goederen toenemen. Kenmerkend voor volmaakt vervangende goederen is dat, als aanvankelijk de prijzen gelijk zijn, bij prijsverlaging van het ene, de vraaghoeveelheid daarnaar toeneemt en die naar het andere goed afneemt. Op deze laatste kenmerken is de definitie gebaseerd aanvankelijk gevolgd door Schultz, dat twee goederen t.o.v. elkaar vervangbaar zijn wanneer prijsverlaging van het ene goed vraagverlaging van het andere tot gevolg heeft, en dat ze complementair t.o.v. elkaar zijn wanneer prijsverlaging van het ene goed leidt tot vraagverhoging van het andere. Daarbij sluit zich aan de definitie dat de goederen t.o.v. elkaar onafhankelijk zijn, wanneer prijsverlaging van het ene geen vraagverandering van het andere tot gevolg heeft. Zoals men ziet is in deze definities geen sprake van volledige complementariteit en volledige vervangbaarheid, zooals die in de twee hierboven gegeven figuren van Irving Fisher tot uitdrukking komt, doch van een verdeling van alle mogelijke gevallen over de twee groepen der complementaire en vervangbare goederen met een overgangsgeval van onafhankelijkheid. Hetzelfde geldt ook voor de oudere definitie die wel gegeven is, en die gebaseerd is op de afhankelijkheid die het grensnut van het ene goed vertoont van de hoeveelheid, in het bezit van de beschouwde persoon, van het andere goed. Deze definitie is verwerpelijk in verband met de onmeetbaarheid van de nuttigheid ${ }^{+}$).

Bij nadere beschouwing blijkt nu de definitie zoals die aanvankelijk door Schultz was aanvaard ook nog aan een willekeurigheid te lijden die vermeden kan worden. De grens tussen de beide gebieden, aangegeven als het geval waarin prijsverandering van het ene goed geen wijziging tot gevolg heeft in de hoeveelheid van het tweede goed die gevraagd wordt is nl. betrekkelijk wille-

4) Men kan nl. aantonen dat een verandering in de maatstaf der nuttigheid tot gevolg zou kunnen hebben dat een paar goederen dat als complementair te beschouwen zou zijn volgens de ene maatstaf vervangbaar zou zijn volgens de andere. 
keurig als men het volgende overweegt. Een prijsverlaging van één goed betekent, bij constant geldinkomen van het subject in kwestie, een verhoging van het reële inkomen en alleen reeds als gevolg daarvan de neiging om in 't algemeen meer te kopen van elk goed. Slechts goederen die uitgesproken vervangingsgoederen van het eerste $z$ ijn zullen een achteruitgang in verbruik vertonen omdat daar de (kleine) toename van het reële inkomen geen compensatie levert. Om de goederen zuiver te onderscheiden naar complementaire en vervangbare kan dan ook beter een correctie worden aangebracht voor de verandering in het reële inkomen. Dit kan gebeuren door een verandering in het geldinkomen aan te nemen die het reële inkomen juist op peil houdt; men spreekt dan van een gecompenseerde prijsvariatie voor het eerste goed. Het criterium voor onafhankelijkheid wordt dan of de gevraagde hoeveelheid van het tweede goed, na deze compensatie, niet veranderd is. En dienovereenkomstig worden de definities van complementaire en vervangbare goederen gewijzigd. Dit is gedaan door Hicks en Allen in hun belangrijke studie ,A Reconsideration of the Theory of Value" (Economica XIV (1934), blz. 52 en 196).

Bij dit alles moet dan nog in het oog gehouden worden dat voor eenzelfde goederenpaar bij de ene prijsstand complementariteit en bij de andere prijsstand vervangbaarheid kan bestaan en dat voor verschillende personen er ook verschil kan bestaan.

Ik heb met opzet deze theoretische kwesties nog even naar voren gebracht omdat in de leerboeken aan de begrippen complementair en vervangbaar nogal eens aandacht wordt besteed. Van zeer groot belang komen ze mij niet voor. Waar het m.i. op aan komt is dat men de grootte der reacties kent, minder of men in een gegeven geval met complementaire dan wel met vervangbare goederen te doen heeft. Dit is dan ook vooral Schultz' werk geweest. En hij knoopt aan de bepaling van de grootte nog een controle vast. Het blijkt $\mathrm{nl}$. dat de vraagverandering naar goed A ten gevolge van een prijsverandering in $B$ en de vraagverandering naar goed $B$ ten gevolge van een prijsverandering in $A$ niet onafhankelijk van elkaar zijn, maar aan een bepaalde formule moeten voldoen.

Alvorens op het statistische gedeelte van het boek in te gaan zij nog even opgemerkt dat Schultz, bij de introductie van de term "dynamisch" wel voorbijgaat aan veel belangwekkends dat de laatste tijd in dit gebied gewrocht is. Hij verstaat onder een 
„dynamische wet van de vraag" alleen een vraagfunctie die met de tijd geleidelijk verandert, bv. door veranderingen in smaak, bevolkingsomvang, enz. Veel belangwekkender zijn de door Frisch dynamisch genoemde vraagfuncties, d.z. vraagfuncties waarbij de gevraagde hoeveelheid van de prijs op een vroeger tijdstip afhangt of van de prijsverandering per tijdseenheid (speculatieve vraag), dan wel, zoals bij duurzame goederen, van de vraaghoeveelheid in een geheel tijdvak (vervangingsvraag).

In hoofdstuk II van zijn eerste gedeelte laat Schultz de verschillende pogingen on vraagcurven uit statistische gegevens te construeren de revue passeren. Hij begint met een goede uiteenzetting van de bekende moeilijkheid dat een stel waarnemingen van bijeenbehorende prijzen en hoeveelheden niet voldoende is om een vraagcurve te vinden. Dat is wel het geval wanneer men op de een of andere wijze weet dat de vraagkromme in de beschouwde periode zich niet gewijzigd heeft. Dan toch moeten alle punten die men in een prijs-hoeveelheids-diagram vaststelt op een en dezelfde kromme liggen, die dan de vraagcurve is. Zulks is het geval als alle andere factoren die, naast de prijs, de gevraagde hoeveelheid bepalen onveranderd zijn gebleven: de bekende ceteris-paribusclausule moet gelden. Alle verdere pogingen om vraagcurven te construeeren bestaan in ò :

1) het aannemen van bepaalde hypethesen over wat die andere factoren hebben gedaan òf

2) het aanbrengen van correcties voor de invloed van die andere factoren.

Typische voorbeelden van de onder 1 genoemde methoden zijn:

1a) de zgn. "tweede methode" van Pigou, die aanneemt dat de beweging in de andere factoren geleidelijk is en

1b) de methode van Leontieff, die aanneemt dat die beweging een toevallige is (eigenlijk: ongecorreleerd is met de beweging in de ,aanbodfactoren").

Voorbeelden van de onder 2 genoemde methoden zijn:

2a) berekeningen waarbij de invloed van de andere factoren a priori bekend is; hier zijn vier gevallen in het bijzonder te noemen:

I. De invloed van de bevolking die als evenredig met die bevolking wordt aangenomen en dus uitgeschakeld wordt door de gevraagde hoeveelheid per hoofd te nemen.

II. De invloed van alle andere prijzen die aldus wordt aan- 
genomen dat per saldo niet de geldprijs van het goed in kwestie voor de vrager doorslaggevend is, maar de „reële prijs”, d.i. de geldprijs gedeeld idoor een (vergelijkbare) algemene prijsindex. Op die wijze wordt dan gecorrigeerd.

III. De invloed van het inkomen. Deze wordt uit budgetstatistieken afgeleid en de vraaghoeveelheid wordt aldus gecorrigeerd.

IV. De invloed van alle geleidelijk zich veranderende factoren. Deze wordt uitgeschakeld door de trend uit te schakelen, hetzij direct, hetzij indirect doordat men opeenvolgende verschillen in de hoeveelheden vergelijkt met opeenvolgende verschillen in de prijzen.

Op deze aprioristische bepalingen van de invloed van sommige factoren is wel wat af te dingen, in het bijzonder op de onder II genoemde. Deze komt, zoals men weet, neer op het aannemen dat de ,money illusion" niet geldt ${ }^{5}$ ).

2 b) de methode van de multipele correlatie ${ }^{0}$ ).

Al deze methoden worden uitvoerig in Schultz' boek uiteengezet en van commentaar voorzien; hij gebruikt voornamelijk de laatste.

In het tweede gedeelte van het werk vindt men de resultaten van metingen van enkelvoudige vraagcurven, verricht door den schrijver. Ze hebben betrekking op suiker, mais, katoen, hooi, tarwe, aardappelen, haver, gerst, rogge en boekweit. Zoals men ziet zijn er dus geen diensten en geen duurzame goederen bij en evenmin industrieel bewerkte goederen. Dit is in zekere zin jammer, omdat een aantal belangrijke vraagstukken van conjunctuurpolitiek voor hun oplossing behoefte hebben aan de kennis van die vraagfuncties. Voor elk der goederen is een aantal uiteenloopende methoden gebruikt, meestal b.v. die van de opeenvolgende verhoudingen (link relatives) en van de trendafwijkingen (trend deviations), waarbij afwisselend lineaire en exponentiële vergelijkingen zijn gebezigd.

In .een aantal gevallen, b.v. katoen, is, naast de prijs en de tijd, nog een andere variabele in de berekening opgenomen, b.v. de industriële conjunctuur. Veelal zijn drie perioden beschouwd, 18751895, 1895-1914 en 1915-1929. Herhaaldelijk zijn de perioden iets anders gekozen. De trends zijn kromlijnig aangenomen en niet

5) Men zie b.v. F. Weinreb, Statistische Bepaling van de Vraagcurve, Haarlem 1936.

6) Voor een eenvoudige uiteenzetting over deze methode zie men ook het zoëven geciteerde boek van Weinreb. 
in alle gevallen bevredigend, te oordelen naar de grafieken. De trends in de opeenvolgende tijdvakken sluiten vaak slecht aaneen. Voor de bepaling van de elasticiteit zal dit in de meeste gevallen geen groot bezwaar zijn.

De elasticiteits-coëfficiënten lopen af en toe nogal uiteen voor de verschillende methoden toegepast op hetzelfde goed. In de onderstaande tabel zijn de mediaanwaarden uit tabel 48 van Schultz verenigd:

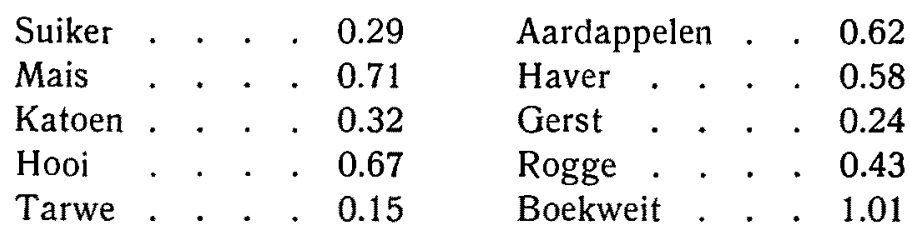

Een in de loop van de periode 1875-1929 afnemende elasticiteit vertonen mais, katoen, hooi, aardappelen en rogge, een toenemende gerst. Bij rogge wordt voor de periode 1915-1929 (met uitzondering van 1917-'21) een zeer hoge elasticiteit gevonden, van omstreeks 2. De bepaling van de vraagcurven voor de afzonderlijke producten wordt voorafgegaan door een nauwkeurige marktbeschrijving en gevolgd door een vergelijking met de bestaande literatuur.

In het derde gedeelte van het boek behandelt Schultz, zoals reeds werd opgemerkt, de vraag naar verwante goederen. Aan de hand van de theorie der complementaire en der vervangbare goederen, hierboven even gememoreerd, tracht hij vast te stellen of bepaalde goederenparen behoren tot de eerste dan wel de laatste categorie en onderzoekt hij ook of de relatie tussen de coëfficiënten waarover $\mathrm{ik}$ al even sprak inderdaad aanwezig is.

De goederengroepen die worden onderzocht zijn:

a) rund-, varkens- en schapenvlees;

b) suiker, thee en koffie en

c) gerst, mais, hooi en haver.

In een eerste hoofdstuk, waar hij een eenvoudiger theorie toepast (aannemende dat de goederen in kwestie slechts een klein deel van het budget in beslag nemen) vindt hij voor de onderlinge verhouding van rund- en varkensvlees de volgende elasticiteiten: 


$$
\begin{aligned}
& \text { Vraag naar rundvlees t.o.v. prijs van rundvlees }-0.49 \\
& \text { " " " " " " varkensvlees + } 0.46 \\
& \text { " "varkensvlees " " " " " }, 0.81 \\
& \text { " " " " " rundvlees + } 0.35
\end{aligned}
$$

Soortgelijke resultaten zijn door het Centraal Bureau voor de Statistiek ook voor Nederland gevonden; de elasticiteiten zijn hier in 't algemeen echter hoger.

Uit bovenstaande cijfers blijkt het vervangende karakter dezer goederen t.o.v. elkaar zeer duidelijk. Ten aanzien van koffie en thee blijkt (deze cijfers zijn voor Canada bestudeerd) eveneens vervanging, terwijl suiker zowel t.a.v. koffie als t.a.v. thee complementair is. De onderzoekingen t.a.v. de zoëven genoemde voedergranen suggereren dat mais t.o.v. hooi complementair zou zijn, en misschien t.o.v. gerst; haver zou t.a.v. gerst en mais vervangend zijn; gerst t.o.v. hooi onafhankelijk, terwijl de verhouding van hooi t.o.v. haver onduidelijk zou zijn. Dergelijke vaststellingen zijn naar mijn gevoelen niet bijster belangrijk; de cijfers zijn o.a. voor de landbouwpolitiek - van belang, maar of er nu onafhankelijkheid wordt aangenomen dan wel de zeer lichte graad van vervangbaarheid of complementariteit die Schultz hier vindt, is betrekkelijk onverschillig.

De controle van de relaties tussen de coëfficiënten doet zien dat er nog wel het een en ander daaraan ontbreekt.

Ik wil het bij deze opmerkingen laten. De ingewijde, maar ook menig belangstellend buitenstaander, zal uit het bovenstaande begrepen hebben dat "The Theory and Measurement of Demand" een standaardwerk van grote betekenis is. 